\title{
无人机倾斜摄影测量技术在城市规划竣工测量中的应用探讨
}

张波

云浮市城市规划测量队

DOI:10.32629/gmsm.v2i2.120

[摘 要] 文章主要针对无人机倾斜摄影测量技术在规划竣工测量中的应用加以研究,结合实际工程案例, 分别从无人机摄影 测量技术、摄影测量技术流程、应用详细探索, 目的在于进一步研究无人机倾斜摄影测量技术在城市规划竣工测量中的应用, 提高规划竣工测量效率。

[关键词] 无人机; 倾斜摄影测量; 数字规划图; 空三加密

无人机倾斜摄影测量技术, 其立体成果真实, 丰富建模 纹理信息, 且具有坐标位置信息。无人机倾斜摄影测量技术 在规划竣工测量中的应用, 帮助其科学规避传统规划竣工测 量中强度大、周期长、重复测量等不足, 更加直观的展现数 据信息, 进一步丰富了规划竣工测量数据。无人机倾斜摄影 作为一种低空获取地理位置信息的拍摄方式, 主要是通过机载 摄像机, 采用垂直、前视、后视、左视、右视等不同拍摄姿态 进行数据采集, 运用惯导系统获取各个相机拍摄瞬间的位置与 姿态信息数据, 再利用专业的数据处理软件将所收集到的数据 信息进行处理,解算平差获取所摄地物的准确地理位置信息。

\section{1 无人机倾斜摄影测量}

无人机作为高新技术, 操作便捷, 作业动机性更强, 其集 成度非常高, 是一体化运行系统, 主要由飞行器、数据通讯系 统、拍摄系统、地面控制系统、飞控系统等组成。无人机倾 斜摄影具备独特性, 拍摄效果真实, 能够反映出地面空间位 置情况, 加上建模纹理信息的提供, 能够帮助规划管理部门 有效完成大比例地形图, 确保规划竣工测量数据的准确性和 时效性, 提高城市规划验收效率。

\section{2 无人机倾斜摄影测量技术流程}

无人机倾斜摄影测量技术中, 数据采集、内业数据处理 最为关键。倾斜摄影测量在规划竣工测量应用中, 以航摄准 备、内业数据处理以及建筑规划图编辑为主。

\section{1 航摄准备阶段}

无人机倾斜摄影测量技术应用之前, 必须做好航摄准备 工作。事前准备工作非常关键, 囊括飞行作业手册所有内容 基础上, 还要对飞行前所有因素逐项展开检查研究, 确保每 一项都符合无人机飞行要求, 待所有检查全部完成才能飞 行。确保无人机倾斜摄影测量过程中, 遥测信号正常, 无人机 摄影功能正常工作, 随时检查数据链路与航线规划, 保证通 畅性、合理性基础上, 确保无人机能够按照规定航线自动控 制飞行高度与角度, 实现等时、等距摄影。

\section{2 内业数据处理阶段}

数字摄影测量技术与无人机融合, 作为无人机与城市规 划竣工测量连接关键点, 进行数字摄影测量技术的内业数据 处理是非常必要的。近些年数据处理基础愈加成熟, 并且数据
处理系统繁多, 比如 Altizure、StreetFactory、 ContextCapture、PhotoMesh 等。数字摄影测量需要制作满 足要求的数据成果, 首先进行搜集航摄资料工作, 必须将航 摄资料进行加密处理, 通过数据处理系统转换为地面布设控 制所需数据, 或者是 POS 数据。其次多外方位元素收集与处 理工作, 整合收集到的 DTM 数据, 利用单张像片映射生成像。 最后, 对生成像加以衔接拼凑, 以及色度处理, 根据工程规划 竣工测量要求对图幅范围适当的调整, 进而将精准的数字影 像图呈现出来。

\section{3 建筑规划图编辑阶段}

在建筑规划图编辑阶段, 相关技术人员应该充分意识到 建筑规划竣工测量中规划图的重要性, 明确其属于成果图类 型, 同时还应该保证建筑规划图的管理与更新工作能及时进 行。对于整个竣工测量工作来说, 只有保证其规划图的准确 性才能够保证建筑规划竣工测量的准确性。一旦工程建筑施 工过程结束, 必须对竣工情况准确掌握、及时定位, 同时向建 筑工程的影像库 (GIS) 中导入 DOM 数据, 观察影像生成的配 准度, 及时调整与处理, 达到合格目的。此外, 在建筑工程竣 工测量中, 增添 Siper-Map DeskPro 也是必要的, 这样不仅能 满足矢量化要求, 还可以确保影像库测量数据录入及时, 提 高建筑工程规划竣工测量质量, 为数据准确性提供双重保 障。

3 城市规划竣工测绘中无人机倾斜摄影测量技术的应用

3.1 无人机倾斜摄影测量技术应用分析

3.1.1 无人机倾斜摄影测量技术, 要求摄影组合应用五 镜头获取倾斜摄影数据, 并且将单镜头焦距设置为规定的大 小, 这样既可以满足航向重叠数字化要求, 又能够满足旁向 重叠度数字化要求, 注意影像地面分辨率, 标准要求必须在 规定范围内。无人机倾斜在摄影测量, 需要地面站软件配合计 算, 多数情况下, 都必须结合实际航摄情况, 确定无人机倾斜摄 影五镜头摄影获取的数据组数, 及时掌握组数对应 POS 数据内 容。

3.1.2 空三加密与自动建模。利用无人机倾斜摄影测量 技术中选择的软件平台为基础, 及时将倾斜摄影数据与外业 像控点进行导入, 并且对数据资源等实施空三加密。这期间 
还要包括密集匹配与联合平差。紧接着利用生成点云, 构建 不规则三角网, 进行 DSM 与全自动纹理进行映射, 获取建筑 规划竣工测量全景三维模型。

3.1.3 数字规划图的采集。在倾斜摄影测量技术应用中, 完成加密与建模程序, 则进入到数字线划图环节。此环节一 般情况下选择 idate 软件, 利用其中的矢量测图模块进行内 业数字线划图采集。无人机倾斜摄影技术通过软件控制获取 数据影响, 进一步提高建筑规划竣工测量数据采集的效 率。无人机倾斜摄影测量中, 不要求佩戴立体眼镜, 只需要 根据自动空三与采集影像生成三维模型, 利用三维信息进 行直接定位。适当对外业调绘工作进行调整, 并且改正内 业设计规划, 参考垂直辅助线、十字辅助线, 控制无人机倾 斜摄影的垂直水平移动。此过程中必须保证采集到的所有 数据真实可靠, 并且十分精准。设置数字规划图采集功能 期间, 合软件中所要求的建筑标准与属性模块, 将矢量成 果导出。

3.1.4 成果数据技术应用。根据 DSM、实景三维模型、 点云等自动生成图像与数据, 核对建筑工程规划竣工测量数 据, 利用数据测量成果, 及时编制相关测绘报告, 完成规划竣 工测量工作。

\section{4 无人机倾斜摄影测量技术应用案例}

\section{1 工程介绍}

某高校校区建设完成, 进入规划竣工验收阶段。项目 位置三面与城市道路相邻, 一面靠近山体, 内部设有教学 楼、图书馆、宿舍楼、运动场馆等, 需要无人机倾斜摄影 测量面积达到 45 万 $\mathrm{m}^{2}$ 。无人机倾斜摄影测量技术主要选 择南方测绘公司六旋翼无人机, 并且以五镜头倾斜相机对 施工地点进行拍摄。空中三角测量、全自动三维建模则选 择 Smart3D。

\section{2 倾斜摄影航线布设、数据获取}

航线布设与数据获取, 结合实际竣工测量要求, 设定好 飞行范围, 科学规划无人机飞行航线, 控制飞行重叠度达到 $85 \%$ 之上, 旁向重叠度达到 $80 \%$ 之上。与此同时, 根据倾斜摄 影航线区域走向布设直线, 与首末航线平行, 确保无人机 倾斜摄影的侧视镜头可以准确获得建筑规划竣工图形。控 制好倾斜摄影相机拍摄角度, 保证无人机倾斜摄影所有物 体都能够立体成像, 延伸无人机航线覆盖范围。航线布设 与实际情况相综合, 设定为 35 条, 高度与间距分别为 $120 \mathrm{~m} 、 10 \mathrm{~m}$, 同时旁向间距控制在 $20 \mathrm{~m}$, 像控点 11 个。此次 建筑工程无人机倾斜摄影测量技术应用, 获取数据为 4 架 次, 照片总数为 14405 张, 并且每张照片都拥有详细的测 绘数据与影像。

\section{3 空三加密}

在进行空中三角测量时, 导入照片, 时同时导入对应的 POS 数据, 更改 Smart3D 系统默认的空三设置, 可提高空中三 角测量解算效率, 具体更改如下在:
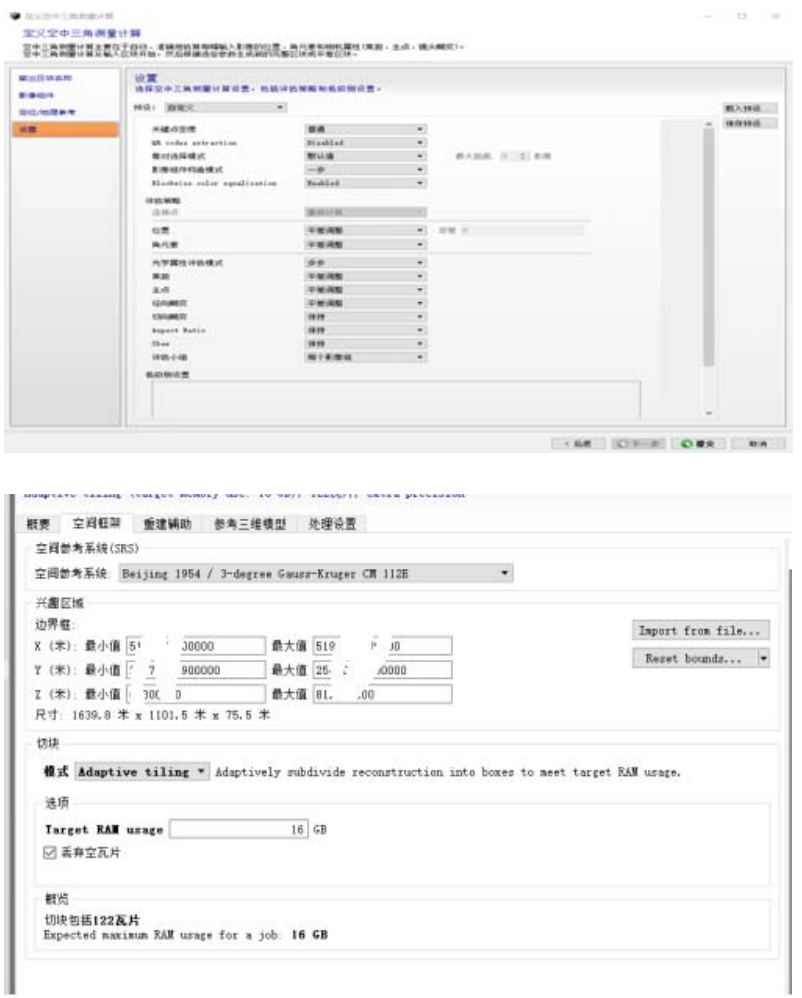

4.4 建模

对三维建模数据成果检查。
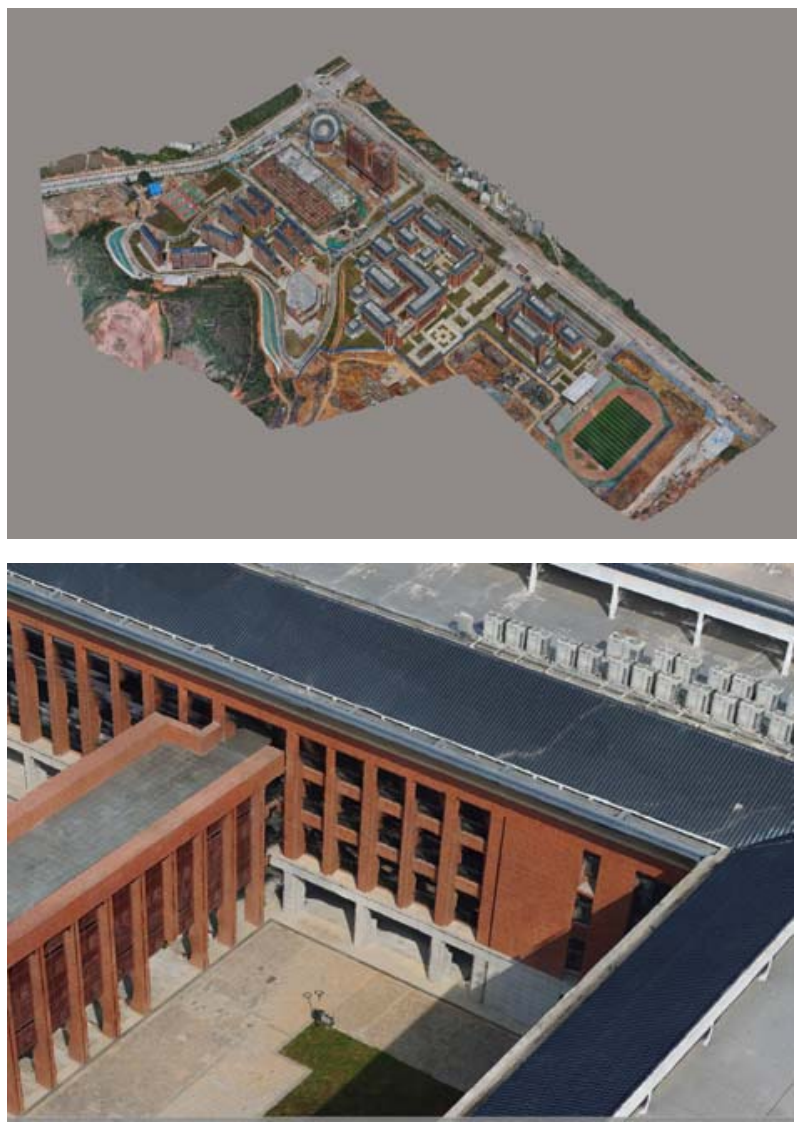

4.5 矢量化 
采用 idate 软件, 根据三维模型完成矢量化测图。

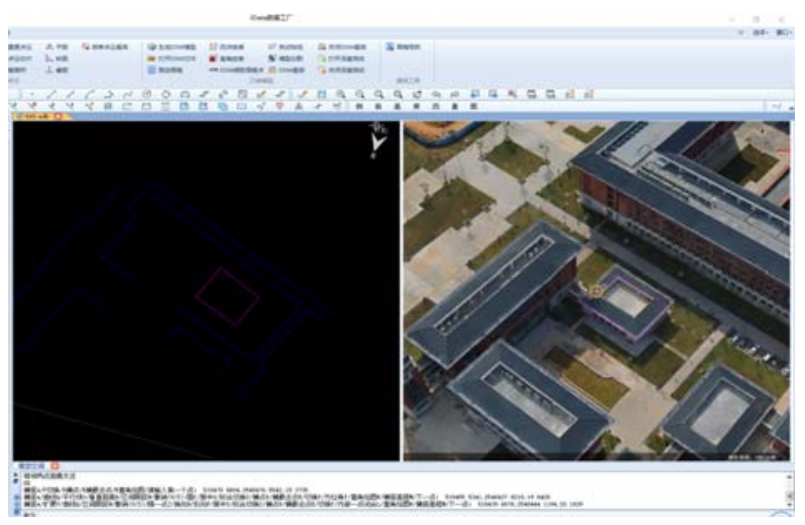

4.6 精度分析

我国《城市测量规范》中对于建筑工程竣工测量地形图 测量数据精度要求, 在竣工测量地物点与相近图根点位置的 误差应满足 1:500 比例尺的测图要求。

在本项目中, 抽样均匀分布的建筑拐角数量为 4 个, 道 路拐角点 4 个。

表 1-点位中误差统计表

\begin{tabular}{c|c|c|c|c|c|c}
\hline \multirow{2}{*}{ 序号 } & \multirow{2}{*}{ 要素类型 } & \multicolumn{2}{|c|}{ 全站仪实测坐标值 } & \multicolumn{2}{|c|}{ 矢量采集坐标值 } & \multirow{2}{*}{$\mathrm{d} / \mathrm{m}$} \\
\cline { 3 - 6 } & X1/m & $\mathrm{Y} 1 / \mathrm{m}$ & $\mathrm{X} 2 / \mathrm{m}$ & $\mathrm{Y} 2 / \mathrm{m}$ & \\
\hline 1 & 房角 & 8410.798 & 8395.378 & 8410.759 & 8395.413 & 0.053 \\
\hline 2 & 房角 & 8395.413 & 8375.301 & 8418.708 & 8375.292 & 0.059 \\
\hline 3 & 房角 & 8375.292 & 8381.609 & 8381.609 & 8381.578 & 0.072 \\
\hline 4 & 房角 & 8426.692 & 8401.686 & 8401.686 & 8401.765 & 0.085 \\
\hline 5 & 道路 & 8412.637 & 8412.194 & 8412.624 & 8412.224 & 0.033 \\
\hline 6 & 道路 & 8397.164 & 8406.019 & 8397.140 & 8406.045 & 0.036 \\
\hline 7 & 道路 & 8416.718 & 8356.650 & 8416.725 & 8356.623 & 0.028 \\
\hline 8 & 道路 & 8434.852 & 8363.806 & 8434.872 & 8363.791 & 0.025 \\
\hline
\end{tabular}

由统计数据可知, 倾斜摄影测量矢量采集数据满足城市 测量规范要求, 并且道路拐角点的精度普遍高于房角点。

\section{7 误差分析}

首先, 确保相片分辨率符合精度要求。相片作为摄影测 量的原始数据, 其数据质量直接影响空中三角测量精度和三 维建模效果, 因此在摄影测量期间必须保证相片分辨率满足 精度需求。同时可对无人机设备航飞参数进行优化与完善, 例如: 调整长焦镜头、控制航拍高度等, 促进地面影像分辨 率的提升, 确保最终获得数据信息具有较强的精准性。其次,
空三加密因素。通常情况下, 自动化 Smart3D 控三加密经常 会出现匹配误差与飞点数据信息误差问题, 使得空三精准性 受到直接影响。因此需要利用人工干预方法, 全面完善空三 数据精度, 确保建筑工程竣工地势图具有良好的完整性与精 准性。最后, 人工采集存在误差。在客观因素影响下, 人工数 据信息收集经常出现各种问题与误差。与此同时若各高程面 存在相同时事物, 就使得进行视觉数据采集期间矢量精准性 得不到良好的保障, 内业施测人员也需要在量测期间根据相 关角度科学调整影像数据信息。因此, 三维模型数据矢量化 工作中, 工作人员需要具有丰富工作经验与操作熟练性, 从 基础上确保矢量收集具有较强精准性。

\section{8 对比生产率}

城市规划竣工测量期间科学运用无人机倾斜摄影测量 方法可有效促进测绘工作效率的快速提升, 同时还可全面降 低施工作业时间, 特别是在通视条件较差的区域中, 倾斜摄 影测量技术的运用可最大限度的展示出其作用。当外业时间 相对较短时, 倾斜摄影测量技术可有效降低自然天气因素产 生的影响与威胁。另外, 多角度三维建模也有着极强的可视 性, 并最大程度的还原出建设项目现场的实际情景, 这时检 核人员就可在不进入到现场就竣工验收审核工作, 从基础上 促进城市规划竣工验收工作效率的快速提升。

\section{5 结束语}

综上所述, 无人机倾斜摄影测量技术的应用, 帮助城市 规划竣工测量提高工作效率, 并且优化测量效果。丰富测绘 成果的同时, 有效控制规划竣工测量成本, 但测量数据精度 仍需进一步提高。

[参考文献]

[1]陈昕.无人机倾斜摄影测量在建筑规划竣工测绘中 的应用 [J].城市勘测,2017,(1):52.

[2]徐维江. 无人机倾斜摄影测量在建筑规划竣工测绘中 的应用[J].山西建筑,2017,(21):201-202.

[3]许新海. 无人机倾斜摄影测量技术在规划竣工测量中 的应用[J].城市勘测,2018,163(02):103-105. 